\title{
Canada lags in standardized protocols for medical labs
}

A

spate of high-profile scandals involving shoddy laboratory

medicine across the nation may serve as a wake-up call for governments and the medical profession to restore and enhance a critical but overlooked link in Canada's health care system.

Both the Canadian Association of Pathologists and the Royal College of Physicians and Surgeons of Canada believe inadequate investment in laboratory medicine has left the discipline overworked, understaffed and ultimately prone to errors and incomplete work. As a consequence, both have launched processes designed to craft national standards, protocols and quality assurance for pathologists, which many have long urged (CMAJ 2008;178[12]:1523-4).

"These are regrettable situations but they have served to highlight a problem we have had for a very long time," says Dr. Jagdish Butany, president of the Canadian Association of Pathologists. "Perhaps we just didn't yell loud enough. But for whatever reason, our concerns have flown under the radar until now.'

Scandals involving erroneous or incomplete work by pathologists (see sidebar, page 126) are now raging in Newfoundland, New Brunswick, Ontario and Manitoba, prompting retesting in more than 60000 cases. Two of those provinces, New Brunswick and Newfoundland, have launched full-scale judicial inquiries to examine the causes of the shoddy work and delays in reporting mistakes to the public.

Dr. Andrew Padmos, chief executive officer of the Royal College of Physicians and Surgeons of Canada, says there is a need to immediately deal with the root problems of these scandals and ensure the system is safe and efficient.

However, Padmos is concerned the inquiries will try to assign sole responsibility to individual pathologists and ignore the fact that the laboratory medicine system has been stretched to the point of breaking. In New Brunswick, the provincial government has asked

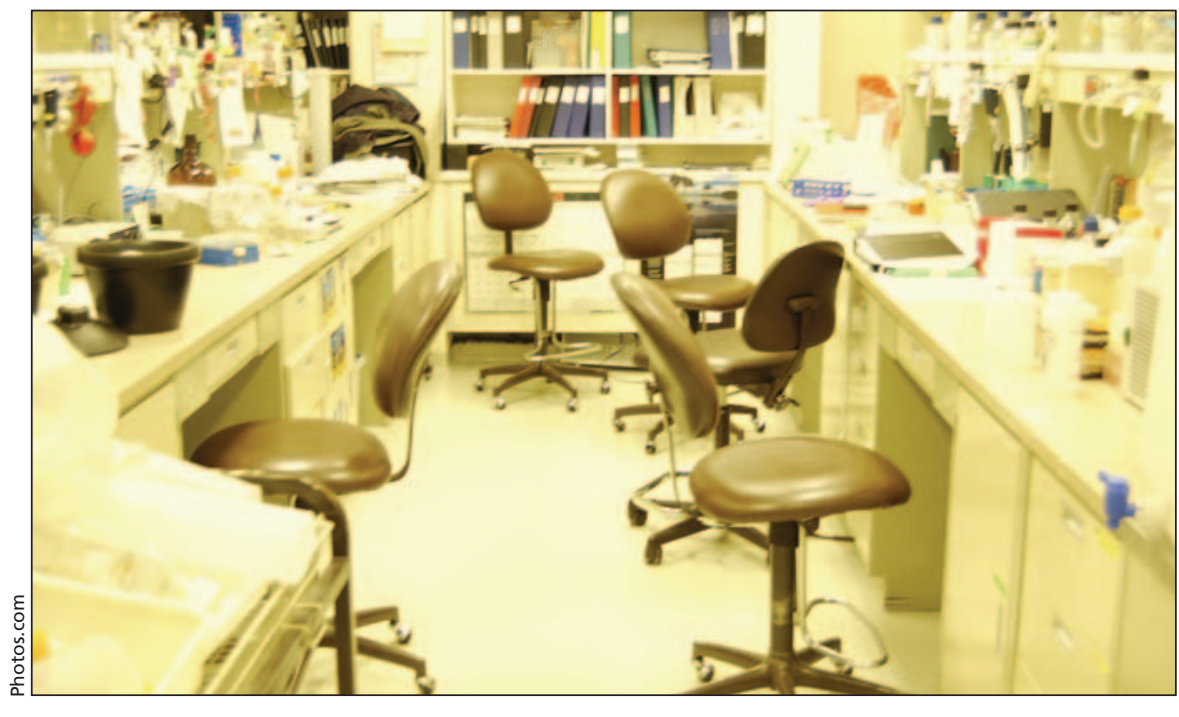

The Canadian Association of Pathologists has estimated that Canada will need upwards of 500 pathologists over the coming decade if it is to meet demand. Compounding the shortfall is the current checkerboard approach to lab accreditation and proficiency testing across the country, although moves are afoot to craft national standards.

the Royal Canadian Mounted Police to investigate the pathologist who produced the incorrect diagnoses.

"I don't think it is fair to try and construct this as individual failure," Padmos says. "It is wrong to try and pin, on individuals, responsibilities which are really systemic."

Dr. Bill Hryniuk, president of the Cancer Advocacy Coalition of Canada, says it has been well understood among oncologists that the existing complement of pathologists is inadequate to meet the demands of a health care system that is constantly introducing new and better laboratory tests to aid in diagnosis and treatment.

Oncologists fear that the effectiveness of promising new cancer drugs could be compromised if laboratories are unable to produce timely and accurate pathology results to indicate which course of treatment is appropriate, he notes. "Labs have always been underfunded. They are always being pushed to do more than they can responsibly do. And they are being pressured to cut corners. This story is not about sloppiness. It's about underfunding."
There are signs, however, that the angst over the rash of incidents across the country is manifesting in positive change for laboratory medicine. The Royal College is organizing a national review involving a coalition of professional organizations, including the Canadian Medical Association, to establish national standards, protocols and quality assurance for pathologists. The Canadian Association of Pathologists, meanwhile, is expected to produce a report this summer with recommendations on how to establish national standards.

Padmos says the terms of the Royal College's review are still being formulated and its launch will likely await the outcomes of the 2 provincial judicial inquiries.

Butany says a shortage of pathologists means many are so overworked they have difficulty keeping up with the barrage of new tests and technologies being developed to hone diagnoses. And while some countries, like the United Kingdom, have already standardized protocols and quality assurance, Canada has lagged far behind in addressing this important area. 


\section{Pathologists under nationwide microscope}

Four jurisdictions have launched reviews of their medical labs as a consequence of frequent errors resulting from lab tests over the course of the past few years. Those 4 :

\section{Miramichi Regional Health Authority, New Brunswick}

A public inquiry is underway to assess the impact of the work of Dr. Rajgopal Menon, 73, the former head of pathology for Miramichi City. The health authority suspended Menon last year after a review of 227 of his cases revealed a high number of incorrect (3\%) and incomplete (18\%) results.

In addition to the public inquiry, the New Brunswick government has retained a laboratory in Ottawa to review 24000 of Menon's cases. It has also asked the Royal Canadian Mounted Police to investigate Menon for possible criminal charges.

\section{Eastern Health Authority, Newfoundland}

The health authority was warned in 2003 by a senior oncologist that the pathology lab in St. John's was producing a high error rate in breast cancer hormone receptor tests. However, the health authority did not divulge the concerns to the public until 2005, after a review by the British Columbia Cancer Institute found widespread problems with lab operations.

A review of test results found that 383 breast cancer patients received the wrong results from hormone receptor tests conducted between 1997 and 2005. More than 100 of the women who received erroneous reports have since died. Another 1000 test results are being reviewed.

A judicial inquiry is now underway to determine why the health authority did not respond sooner to the warnings about the quality of work done in its lab, and why it waited so long to warn the public. As well, 100 of the patients have launched a class-action lawsuit.

\section{Grey Bruce Health Services, Ontario}

A standard internal review in early 2008 of the work of Dr. Barry Sawka turned up a number of concerns about accuracy. As a result, the Grey Bruce Health Authority asked a London hospital to review 600 of Sawka's cases. That review found an error rate of nearly $6 \%$, including some missed cancer diagnoses.

In the wake of the results, Sawka was released and more than 40000 cases he handled over 14 years are being reviewed. The Ontario College of Physicians and Surgeons is also investigating.

\section{Winnipeg Regional Health Authority, Manitoba}

A review in March 2008 of the work of Dr. Robert Stark found errors in 10 of 35 complex cancer cases. Stark, the former head of pathology at Winnipeg's St. Boniface Hospital, was put on leave while another 700 of his cases were reviewed.

The Authority has pledged to announce the results on an ongoing basis. However, questions persist about whether the hospital and health authority had earlier warnings about Stark's work.

Stark was sued in 1999 by a Winnipeg woman who was wrongly diagnosed with pancreatic cancer and told she had a year to live based on Stark's work. It was only after the woman underwent surgery and chemotherapy that she found out she never had cancer. The case was settled out of court for $\$ 200000$.

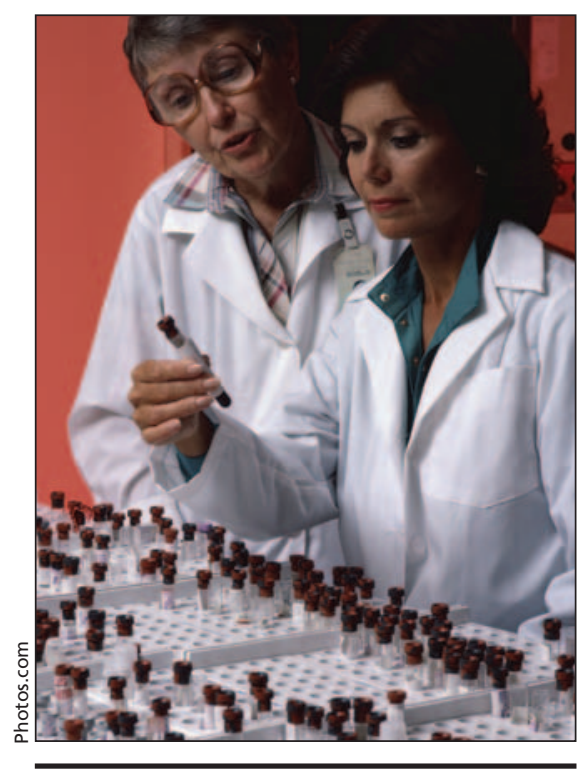

Calls have been made for a national body to oversee accreditation of laboratories in Canada.

"We simply do not have a good, single set of criteria for our work," Butany says.

Individual provinces have moved quickly to address some of the root causes of understaffing. In Newfoundland, for example, Premier Danny Williams announced in May 2008 that salaries for pathologists would increase substantially to help recruit and retain the specialists needed to maintain the province's laboratory system.

A consultant's report found that St. John's suffered from an $80 \%$ turnover rate between 1996 and 2005. Pathologists complained that one of the reasons for this was low salaries; at the time the problems were identified in the Eastern Health Authority, the top paid pathologist in Newfoundland was earning \$235000 annually, which was $\$ 100000$ less than a starting pathologist's salary in Ontario.

With salary increases of up to $\$ 133$ 000, Newfoundland has gone from the bottom of the national wage scale to the top, Butany says. But salaries remain extremely low in the rest of Atlantic Canada, as well as in Quebec, where there has been an exodus of pathologists to other parts of the country, Butany adds. - Dan Lett, Winnipeg, Man. 